Article

\title{
How Do Rural Communities Sustain Sanitation Gains? Qualitative Comparative Analyses of Community-Led Approaches in Cambodia and Ghana
}

\author{
Jessica Tribbe ${ }^{1, *(\mathbb{D})}$, Valentina Zuin ${ }^{2}$, Caroline Delaire ${ }^{1}$, Ranjiv Khush ${ }^{1}\left(\mathbb{D}\right.$ and Rachel Peletz ${ }^{1}$ (I) \\ 1 The Aquaya Institute, San Anselmo, CA 94960, USA; caroline@aquaya.org (C.D.); ranjiv@aquaya.org (R.K.); \\ rachel@aquaya.org (R.P.) \\ 2 Division of Social Science, Yale-NUS College, Singapore 138527, Singapore; valentina.zuin@yale-nus.edu.sg \\ * Correspondence: jessica@aquaya.org; Tel.: +1-(513)314-9254
}

\section{check for}

updates

Citation: Tribbe, J.; Zuin, V.; Delaire,

C.; Khush, R.; Peletz, R. How Do

Rural Communities Sustain

Sanitation Gains? Qualitative

Comparative Analyses of

Community-Led Approaches in

Cambodia and Ghana. Sustainability

2021, 13, 5440. https://doi.org/

$10.3390 /$ su13105440

Academic Editor: Craig Anthony

(Tony) Arnold

Received: 3 April 2021

Accepted: 11 May 2021

Published: 13 May 2021

Publisher's Note: MDPI stays neutral with regard to jurisdictional claims in published maps and institutional affiliations.

Copyright: (C) 2021 by the authors Licensee MDPI, Basel, Switzerland. This article is an open access article distributed under the terms and conditions of the Creative Commons Attribution (CC BY) license (https:// creativecommons.org/licenses/by/ $4.0 /)$.

\begin{abstract}
Community-led Total Sanitation (CLTS) is a popular intervention for eliminating open defecation in rural communities. Previous research has explored the contextual and programmatic factors that influence CLTS performance. Less is known about the community-level conditions that sustain latrine coverage and use. We hypothesized three categories of community conditions underlying CLTS sustainability: (i) engagement of community leaders, (ii) follow-up intensity, and (iii) support to poor households. We evaluated these among communities in Cambodia and Ghana, and applied fuzzy-set Qualitative Comparative Analysis (fsQCA) to identify combinations of conditions that influenced current latrine coverage and consistent latrine use. In Cambodia, latrine coverage was highest in communities with active commune-level leaders rather than traditional leaders, and with leaders who used casual approaches for promoting latrine construction. Latrine use in Cambodia was less consistent among communities with intense commune engagement, higher pressure from traditional leaders, high follow-up and high financial support. In Ghana, by contrast, active leaders, high follow-up, high pro-poor support, and continued activities post-implementation promoted latrine coverage and consistent use. The different responses to CLTS programming emphasize that rural communities do not have homogenous reactions to CLTS. Accounting for community perceptions and context when designing community-led interventions can foster longterm sustainability beyond short-term achievement.
\end{abstract}

Keywords: CLTS; rural sanitation; fsQCA; behavior change; Ghana; Cambodia

\section{Introduction}

Safe sanitation is a basic human right and essential for improving public health. The Sustainable Development Goals (SDGs) include the elimination of open defecation (OD) and the improvement of sanitation services as global public health priorities. Since 2000 , open defecation decreased from $21 \%$ of the global population to $9 \%$ [1]. Despite this progress, as of 2017, approximately 673 million people still practiced open defecation, of whom $90 \%$ resided in rural areas of sub-Saharan Africa and Asia [1].

For the past twenty years, governments and development organizations have applied the principles of Community-led Total Sanitation (CLTS) to eliminate open defecation in rural communities [2]. CLTS advocates changes in social norms and sanitation practices across entire communities, as opposed to focusing on individuals or households. The intervention includes elements of participatory methods (participatory rural appraisal) with an emphasis on being community-led [3]. A trained external facilitator leads the community through a set of activities known as "triggering" intended to elicit feelings of shame and disgust and ignite community-led actions to eliminate open defecation. The facilitator continues to follow up after triggering to support these community-led processes, which might include toilet construction, development of local sanctions, and adoption of 
other hygienic behaviors such as handwashing and proper disposal of child feces. These efforts continue until the community has eliminated open defecation completely (i.e., all households use latrines consistently) and achieved high coverage of latrines (i.e., the proportion of households with a latrine, for which the threshold varies by country). At this point, government officials declare the community open defecation free (ODF) and provide a government certification as well as a community celebration [3].

Despite mixed evidence regarding its effectiveness in achieving health outcomes and sustaining ODF communities, CLTS remains a popular intervention [4-6]. Furthermore, a 2018 desk review of CLTS found limited evidence linking CLTS interventions to health outcomes; the few studies that do exist vary widely in their assessment of CLTS's impact on health outcomes, namely diarrhea and child growth [7]. In examples where CLTS has led to improved sanitation, researchers and implementers have linked CLTS's success to household and community characteristics, enabling environments, program implementation methods, and other contextual factors [8].

A key challenge of CLTS is sustaining sanitation gains after ODF achievement, which is currently poorly understood [9]. Better information on the specific community mechanisms necessary to sustain behavior change would guide implementers on how to incorporate strategies for sustainability into program design [7], and may also provide insight into sustaining other types of community-driven development interventions in rural communities. This study investigated the conditions that influence ODF sustainability in rural Cambodia and Ghana. The conditions selected reflect factors related to program implementation and the enabling environment that are frequently hypothesized to influence CLTS success in peer-reviewed and gray literature [7]. In addition, these conditions are linked to common implementation strategies already used by CLTS practitioners $[3,4,7]$. The conditions fall into three categories: (i) community leadership, (ii) follow-up activities (including post-triggering and post-ODF), and (iii) support to poor households (internal or external), including financial support. We review the literature regarding each of these three categories below.

This study applies fuzzy-set qualitative comparative analysis (fsQCA) to examine how specific conditions influence CLTS outcomes in combination with one another.

\subsection{Community Leadership}

There is a growing body of evidence that community leaders play important roles in ODF achievement and sustainability [7,10-13]. Leaders include traditional leaders (i.e., community chiefs), natural leaders (i.e., community members who are selected by the community or volunteer), and political leaders (i.e., elected officials). Active natural and traditional leaders resulted in higher latrine coverage in Ghana [14,15]. Communities with trusted community leaders achieved ODF more quickly in Indonesia [10]. An evaluation of CLTS programs in eight Sub-Saharan African countries suggested that female natural leaders may be important for ODF sustainability, due to their continued follow-up postODF [13]. In Bangladesh, households were at a greater risk of abandoning their latrines and reverting to open defecation when local leaders were not involved in sanitation [16]. In a study of 116 ODF communities across Ethiopia, Kenya, Sierra Leone and Uganda, implementers identified that strong traditional and natural leaders were key drivers of sustained latrine use because they encouraged households to help their neighbors with latrine construction [17]. While there is limited evidence on the varied strategies and activities that leaders use when ODF status is sustained, two previous studies found that leader strategies that included shaming and coercion were not effective at increasing latrine use [18] and had the potential to have negative psycho-social effects on individuals in Cambodia [19].

\subsection{Follow-Up Activities}

Follow-up activities occurring after CLTS triggering (i.e., post-triggering follow-up) and after ODF achievement (i.e., post-ODF follow-up) also have the potential to influence 
CLTS outcomes, though sanitation programs rarely include post-ODF follow-up. A study comparing sanitation interventions in four countries found that the highest reductions in open defecation occurred where there was the most intense follow-up post-triggering [20]. In Ghana, a randomized control trial of CLTS suggested that latrine coverage increased by $11.5 \%$ with every additional follow-up visit post-triggering [15]. Conversely, there are also examples of programs with minimal post-triggering follow-up that also have achieved significant reductions in open defecation: a study in Tanzania with only a single government-led visit achieved a 54\% reduction in open defecation [18].

Various actors can conduct post-triggering and post-ODF follow-up. These include individuals from outside the community (such as government or NGO staff) and individuals from within the community (such as traditional or natural leaders) [3]. The type of actor, whether local government official or external NGO staff, conducting follow-up can also influence effectiveness. For example, toilet construction in Indonesia increased by six percentage points in communities where NGOs managed triggering and follow-up, compared to no significant increases in similar communities managed by local government staff [21].

\subsection{Financial and Pro-Poor Support}

CLTS conventionally does not include subsidies [3], and there is some evidence that communities with a history of prior subsidies do not respond well to CLTS interventions [22-25]. An evaluation of CLTS programs in six countries in South and Southeast Asia reported that subsidies often created a barrier to ODF achievement: subsidies to poor households caused disputes among community members, and rumors of subsidies in neighboring communities "dampened the spirit of self-mobilization" [10,26]. Nevertheless, there is increasing recognition that some form of external assistance is needed for the poorest and most vulnerable households to afford improved sanitation [27-29]. Poorer households are more likely to build less durable latrines that are prone to collapse [30,31], which results in reversion to open defecation [9,32,33]. A few studies have found that targeting sanitation subsidies to poor households can increase toilet ownership: toilet discounts to the poor in Bangladesh increased toilet ownership by $12 \%$ [34], and a post-installation rebate to the poor in Vietnam resulted in a 17 percentage-point increase in private septic tank ownership [35].

In addition to financial external support, community members may assist poor or vulnerable neighbors in installing sanitation facilities, either through in-kind or financial contributions (which we refer to as 'internal support'). A study in 116 communities across four countries found that "inter-household support" was twice as frequent in ODFsustained communities [17] than in those communities that reverted to open defecation (or lost ODF status).

\section{Materials and Methods}

\subsection{Study Sites and CLTS Programs}

We conducted this study in Cambodia and Ghana from November 2018 to July 2019, beginning with Cambodia and followed by Ghana. We selected these two countries because of their established CLTS programs, and because they offered contrasting contexts. In Cambodia, we selected rural provinces and districts where CLTS activities were implemented by a consortium of NGO and government partners called the Cambodia Rural Sanitation and Hygiene Improvement Programme (CRSHIP), funded by the Global Sanitation Fund, a pooled global fund created by the Water Supply and Sanitation Collaborative Council (WSSCC). Phase 1 of CRSHIP (2011-2016) aimed to increase access to improved sanitation facilities and promote proper hygiene practices among rural communities in central provinces of Cambodia through CLTS and other approaches (e.g., sanitation marketing). Phase 2 of CRSHIP (2018-present) focused on the needs of vulnerable groups and targeted additional provinces not included in the first phase [36]. In Ghana, we selected rural provinces and districts where CLTS activities were implemented by the international NGO 
Global Communities through two USAID-funded initiatives: WASH for Health (W4H) and Resiliency in Northern Ghana (RING). In Ghana, the RING project included CLTS as one component of an intervention to improve the nutrition and livelihood status of vulnerable households in the country's Northern Region. W4H aimed to increase access to water, sanitation and hygiene across five regions of Ghana, including three districts in the Northern Region.

Within these programs, we selected our study areas in collaboration with local government (Kampong Cham and Kampong Speu provinces in Cambodia and four districts in Ghana: Sawla Tuna Kalba, East Mamprusi, West Mamprusi, and Nanumba North) based on the following criteria: (i) participation in CLTS implementation; (ii) high to average ODF achievement relative to other provinces or districts (i.e., $\geq 50 \mathrm{ODF}$ communities per province in Cambodia, $\geq 25$ ODF communities per district in Ghana); (iii) typical levels of local government or implementing partner capacity and funding for CLTS implementation (based on information from implementing partners); and (iv) languages or dialects that were spoken by field team members (Khmer in Cambodia; either Dagaare/Waali, Dagbani, English, Kokomba, Mampruli, Lekpakpa, and/or Twi languages in Ghana).

\subsection{Community Selection}

\subsubsection{Eligibility Criteria}

Within the identified provinces and districts, we shortlisted potential communities based on triggering date, community size, and CLTS implementation quality (Cambodia only) (details provided in Tables S5 and S6). A community, or phum, in Cambodia is the lowest administrative level below the commune and consists of a grouping of households led by a single community chief. In Cambodia, we targeted communities that were triggered between two and six years prior to our data collection and had a community size (i.e., number of households) within one standard deviation of the average, i.e., between 66 and 284 households. In Ghana, we targeted communities that were triggered between two to five years prior to our data collection and had at least 15 households but not more than 100 households (larger communities were often sub-divided for CLTS triggering).

\subsubsection{Sampling Strategy}

Using data provided by the implementing partners, we conducted purposive sampling to establish three categories of communities: (i) communities that achieved and sustained ODF (i.e., declared ODF at least 12-15 months prior to data collection according to the respective national definitions, and maintained sufficient latrine coverage to meet the national definition), (ii) communities that achieved ODF according to national criteria but did not sustain (i.e., declared ODF at least 12-15 months prior, but no longer had sufficient latrine coverage to meet the national definition as self-reported by community leaders), or (iii) communities that never achieved ODF (i.e., triggered at least two years prior but never declared ODF). Using information collected from key informants (local authorities and organizations involved in community triggering and monitoring), we also sought variability across our three categories of interest: leadership, follow-up, and financial/pro-poor support. Prior to data collection, we screened each community for eligibility through phone calls or rapid interviews with community leaders and CLTS facilitators (42 in Cambodia, 58 in Ghana). Ultimately, we selected 13 communities in Cambodia and 15 in Ghana (Figure 1). 


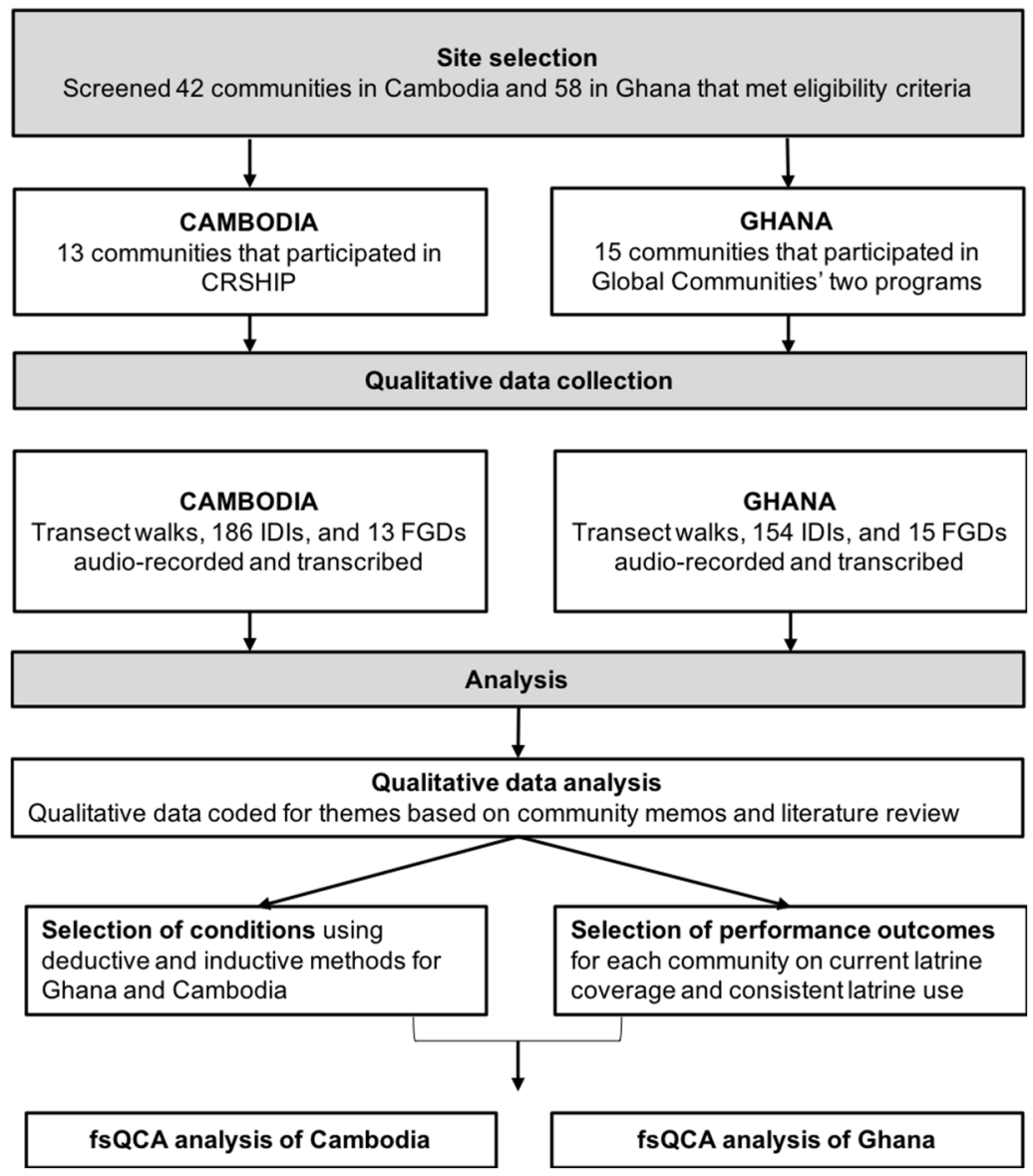

Figure 1. Study design overview. CRSHIP = Cambodia Rural Sanitation and Hygiene Improvement Program; ODF = open defecation free; IDIs = in-depth interviews; FGDs = focus group discussions; $\mathrm{fsQCA}=$ fuzzy-set Qualitative Comparative Analysis.

\subsection{Qualitative Data Collection}

In each selected community, we conducted transect walks, semi-structured in-depth interviews (IDIs), and focus group discussions (FGDs) until we reached saturation (i.e., no additional new information was collected with additional data collection). With the assistance of key informants, we identified participants for in-depth interviews: individuals responsible for triggering activities, district and provincial officials, traditional and natural leaders, and households (e.g., early and late toilet adopters, poor and vulnerable households). We also conducted one FGD per community and purposively selected households that would help triangulate information gathered during IDIs. Therefore, FGD participant types varied depending on the community, but we requested that community leaders (traditional and natural) did not participate in FGDs. We established equal participation of men and women for individual interviews and FGD where possible, but were unable to hold separate FGDs for men and women. Members of our research teams conducted interviews in the participants' language of preference. In Cambodia, the research team conducted 186 in-depth interviews and 13 FGDs, totaling approximately $140 \mathrm{~h}$ of audiorecordings. In Ghana, the research team conducted 154 in-depth interviews and 15 FGDs, totaling approximately $175 \mathrm{~h}$ of audio-recordings. We also collected documents from implementing agencies, donors, and local officials to triangulate information on implementation processes, triggering dates, ODF status, and community size.

\subsection{Ethical Review}

Our study protocol was determined to be exempt from full review by the Western Institutional Review Board (under 45 CFR $§ 46.101(b)(2)$ of the Federal Common Rule in 
the U.S.) and Cambodia's National Ethics Committee for Health Research. In Ghana, our study protocol was approved by the Council for Scientific and Industrial Research (RPN 002 CSIR-IRB 2019). Researchers obtained informed verbal consent from all interview and focus group participants prior to beginning each interview and audio-recording. To protect the confidentiality of our study participants, we have not provided the community names; in data tables, we specify communities with the first letter of their country and an identification number.

\subsection{Data Analysis}

We hired independent contractors in both countries to complete verbatim transcription and translation of interviews and FGDs into English, which we then coded using the Nvivo software (QSR International, Chadstone, Victoria, Australia). We identified themes for qualitative coding both deductively from our previous literature review on the three categories that we identified as important for achieving ODF sustainability (leadership, follow-up, and financial/pro-poor support) and inductively on new themes that emerged during data collection.

For data analysis, we applied fuzzy-set Qualitative Comparative Analysis (fsQCA) to analyze the relationships between conditions and CLTS program outcomes in each community [37]. Using set theory and fuzzy logic (which allows for continuous rather than binary scores between 0 and 1), fsQCA identifies combinations of conditions (called pathways in QCA terminology) that contribute to an outcome of interest; there can be multiple pathways associated with one outcome. QCA examines relationships between conditions and outcomes, but does not establish rigorous causality.

After completing the coding, we generated a list of potential causal conditions under our three categories of interest. This resulted in 24 initial conditions for Cambodia. In line with best practices for QCA for studies with 10-40 cases (communities in our study), we narrowed our list of conditions [37]. In Cambodia, we eliminated eight conditions with limited variability (i.e., the condition did not vary significantly across cases) [38], combined six conditions with other conditions or outcomes, and dropped four conditions due to insufficient data (See Figure S1). In Ghana, we started with a fewer number of conditions (13) based on our experience in Cambodia, and then eliminated three conditions with limited variability [38], combined two conditions with other conditions, and dropped two conditions during the analysis as their inclusion in the model did not improve solution consistency for either outcome (See Figure S2). Our final set of conditions were organized in three categories, but varied between Ghana and Cambodia due to the different contexts (Table 1).

With respect to community leadership (category 1), we selected four conditions: commune engagement in Cambodia, which reflected the extent to which Commune Council members were engaged in sanitation at the community level; traditional leader pressure in Cambodia which measured the level of pressure traditional leaders applied to households to encourage latrine construction; traditional leader engagement in Ghana, which measured the level of involvement of traditional leaders in sanitation in the community (regardless of the type of strategy applied); and natural leader engagement in Ghana, which assessed the levels of activity among natural leaders in Ghana.

With respect to follow-up activities (category 2), we selected two conditions: NGO/ CLTS facilitator follow-up in both countries, which evaluated the intensity of post-triggering follow-up by external actors; and internal post-ODF follow-up in Ghana, which determined the intensity of post-ODF follow-up by natural or traditional leaders. We did not examine post-ODF follow-up by external actors in either country because we found that external actors generally conducted minimal post-ODF follow-up, which is consistent with previous research results $[39,40]$. 
Table 1. Definitions of program sustainability outcomes and relevant conditions in Cambodia and Ghana.

\begin{tabular}{|c|c|c|c|c|}
\hline Category & Outcomes/Conditions & Scale & Cambodia Definitions & Ghana Definitions \\
\hline \multirow{3}{*}{$\begin{array}{l}\text { Category 1: } \\
\text { Community } \\
\text { Leadership }\end{array}$} & Commune Engagement & Four-point & $\begin{array}{c}\text { Level of engagement of commune } \\
\text { Council members in sanitation at } \\
\text { the community level } \\
\text { post-triggering. }\end{array}$ & $\begin{array}{l}\text { N/A (no communes in } \\
\text { Ghana) }\end{array}$ \\
\hline & $\begin{array}{l}\text { Traditional Leader } \\
\text { Pressure (Cambo- } \\
\text { dia)/Traditional Leader } \\
\text { Engagement (Ghana) }\end{array}$ & Four-point & $\begin{array}{l}\text { Intensity of pressure applied by } \\
\text { community leaders to households } \\
\text { post-triggering (includes } \\
\text { Community Chief, Deputy Chief, } \\
\text { or Community Focal Point) }\end{array}$ & $\begin{array}{c}\text { Activity level of traditional } \\
\text { leaders, namely Community } \\
\text { Chiefs, in sanitation activities } \\
\text { post-triggering. }\end{array}$ \\
\hline & $\begin{array}{l}\text { Natural Leader } \\
\text { Engagement }\end{array}$ & Four-point & $\begin{array}{l}\text { N/A (no natural leaders in } \\
\text { Cambodia) }\end{array}$ & $\begin{array}{l}\text { Activity level of natural } \\
\text { leaders in sanitation } \\
\text { activities post-triggering. }\end{array}$ \\
\hline \multirow{2}{*}{$\begin{array}{l}\text { Category 2: } \\
\text { Follow-up } \\
\text { Activities }\end{array}$} & $\begin{array}{l}\text { NGO (Cambodia)/ } \\
\text { CLTS Facilitator } \\
\text { follow-up (Ghana) }\end{array}$ & Four-point & $\begin{array}{l}\text { Intensity of follow-up by NGOs } \\
\text { post-triggering. (Not limited to } \\
\text { CLTS implementing partner.) }\end{array}$ & $\begin{array}{l}\text { Intensity of follow-up by } \\
\text { CLTS facilitators or other } \\
\text { external actors } \\
\text { post-triggering. }\end{array}$ \\
\hline & $\begin{array}{l}\text { Internal follow-up } \\
\text { post-ODF (Ghana) }\end{array}$ & Four-point & $\begin{array}{l}\text { N/A (This condition was dropped } \\
\text { due to insufficient variability) }\end{array}$ & $\begin{array}{l}\text { Activity level of natural } \\
\text { leaders or traditional leaders, } \\
\text { or both, post-ODF (at the } \\
\text { time of the research). }\end{array}$ \\
\hline \multirow{3}{*}{$\begin{array}{c}\text { Category 3: } \\
\text { Financial/ } \\
\text { Pro-poor Support }\end{array}$} & Financial Support & Four-point & $\begin{array}{l}\text { Amount of financial support, such } \\
\text { as subsidies, latrine materials or } \\
\text { loans, received by the community } \\
\text { (pre- or post-ODF; does not } \\
\text { include sanitation marketing offers } \\
\text { of low-cost latrines). }\end{array}$ & $\begin{array}{l}\text { N/A (This condition was } \\
\text { dropped due to insufficient } \\
\text { variability) }\end{array}$ \\
\hline & $\begin{array}{l}\text { Pro-poor support } \\
\text { (Cambodia)/ Internal } \\
\text { Support (Ghana) }\end{array}$ & Four-point & $\begin{array}{l}\text { Extent to which financial support } \\
\text { or other strategies were } \\
\text { intentionally targeted to poor or } \\
\text { vulnerable households. }\end{array}$ & $\begin{array}{l}\text { Level of engagement of } \\
\text { community members in } \\
\text { sanitation activities, } \\
\text { including supporting } \\
\text { neighbors to construct } \\
\text { latrines, or ensuring that } \\
\text { poor and vulnerable } \\
\text { households were supported. }\end{array}$ \\
\hline & $\begin{array}{l}\text { Subsidies before } \\
\text { triggering }\end{array}$ & Binary & $\begin{array}{l}\text { Presence of subsidies prior to } \\
\text { CLTS activities in the community. }\end{array}$ & $\begin{array}{l}\mathrm{N} / \mathrm{A} \text { (no communities had } \\
\text { received previous subsidies) }\end{array}$ \\
\hline Other & $\begin{array}{l}\text { Women engaged in } \\
\text { sanitation }\end{array}$ & Four-point & $\begin{array}{l}\text { N/A (This condition was dropped } \\
\text { due to insufficient variability) }\end{array}$ & $\begin{array}{l}\text { Engagement of women in } \\
\text { sanitation activities such as } \\
\text { triggering, the decision to } \\
\text { construct latrines, } \\
\text { maintaining latrines over } \\
\text { time, or in leadership } \\
\text { positions (i.e., natural } \\
\text { leaders). }\end{array}$ \\
\hline \multirow[t]{2}{*}{ Outcomes } & $\begin{array}{l}\text { Outcome 1: Current } \\
\text { Latrine Coverage }\end{array}$ & Continuous & $\begin{array}{l}\text { Current number of latrines } \\
\text { divided by number of households. }\end{array}$ & $\begin{array}{l}\text { Current number of latrines } \\
\text { divided by number of } \\
\text { compounds (In Ghana, a } \\
\text { compound is grouping of } \\
\text { households; the number of } \\
\text { households per compound } \\
\text { varied per community.). }\end{array}$ \\
\hline & $\begin{array}{l}\text { Outcome 2: Consistent } \\
\text { Latrine Use }\end{array}$ & Four-point & \multicolumn{2}{|c|}{$\begin{array}{l}\text { Prevailing latrine use behaviors in the community compared to } \\
\text { open defecation behaviors. }\end{array}$} \\
\hline
\end{tabular}


For financial and pro-poor support (category 3), we selected conditions that differed between Ghana and Cambodia due to differences in access to markets, use of subsidies, and types of latrines. In Cambodia, we assessed three conditions: financial support (sanitationrelated subsidies or loans provided to communities at any stage, either pre-triggering, or pre- or post-ODF); pro-poor support, or the extent to which financial support was intentionally provided specifically to poor households for sanitation; and subsidies before triggering, which considered the timing of financial support and indicated whether any sanitation-related subsidies were provided to communities before CLTS activities began in the community. Because previous literature found that subsidies prior to CLTS can create barriers to CLTS success [22-25], we chose to analyze whether or not communities in Cambodia had been provided subsidies prior to triggering as a separate condition in our analysis. In Ghana, financial support was limited to the occasional free provision of plastic latrine slabs, and we found minimal use of subsidies prior to CLTS. Instead, we assessed the following condition: levels of internal support, such as neighbors helping neighbors to construct latrines. In Ghana, we also included an additional condition, women engaged in sanitation, which did not fall directly under our three categories but did emerge as an important consideration for sustainability.

We examined two outcomes, latrine coverage (a continuous variable) and latrine use (a categorical variable) (Table 1), recognizing that latrine coverage does not necessarily indicate latrine use $[7,27]$. The national definitions for ODF were different in each country: in Cambodia, at least $85 \%$ of households in the community should have a functional improved latrine [41], and in Ghana, at least $80 \%$ of households in the community should own a functional improved latrine with handwashing facilities [42]. In both countries, households without their own latrines should share with other households. For latrine coverage (our first outcome) in Ghana, rather than using the official national definition, we determined latrine coverage using the calculation understood by natural leaders in the community, and self-reported during our visits: the number of latrines divided by the number of compounds (a grouping of number of households often enclosed by a wall). Our discussions with natural leaders and CLTS facilitators indicated that this was often how coverage was assessed in practice, including for ODF certification. In Cambodia, we assessed coverage with the number of latrines divided by the number of households, as reported by community leaders. When conducting the QCA analysis, we treated latrine coverage as a continuous variable, but considered all communities with $\geq 85 \%$ coverage in Cambodia and $\geq 75 \%$ coverage (of compounds) in Ghana as "high" latrine coverage communities. For Cambodia, our threshold (85\%) matched the national threshold for ODF; for Ghana, we selected a lower threshold (75\% compared to $80 \%$ for the national threshold) based on natural breakpoints in coverage among the study communities.

To define latrine use (our second outcome), we examined how consistently households used latrines rather than practicing open defecation. We also considered whether households preferred to share latrines or practice open defecation when their latrine was not available or collapsed/broken. We assessed consistent latrine use on a four-point scale through qualitative data collection (Table 1).

Following the established fsQCA methodology, we scored communities (called cases in QCA terminology) on each condition and outcome according to a pre-determined scoring rubric (Tables S1 and S3) [43]. We scored most conditions and outcomes on a four-point scale ranging from 0 to 1 (i.e., $0,0.37,0.67$, or 1 ), with the exception of one outcome which was continuous (latrine coverage), and one condition which was binary (subsidies before triggering) (Table 1). Two members of the research team independently scored the conditions and outcomes in each case. When there were disagreements in the scores, the researchers reviewed the case together and discussed their analyses until they reached an agreement. We then summarized scores in a or matrix (Tables S2 and S4) and used the open-source fsQCA software for analysis [37]. To identify the pathways for each outcome, we applied the iterative process of using case knowledge and evaluating two goodness of fit parameters: consistency, which measures the degree to which cases 
that have the condition (or combination of conditions) also have the outcome of interest, and coverage, which measures the proportion of cases with the outcome covered by the pathways [38]. Following the standard practices of QCA, we did not consider any pathways with a consistency score lower than 0.8 , and all pathways reflect the intermediate solution produced by the fsQCA software (i.e., a moderate level of assumptions are made by the software) [37]. It is important to note that the fsQCA coverage score is not directly proportionate to the number of cases in the pathway because cases may exhibit partial outcomes or conditions (i.e., scores of 0.33 or 0.67 ). To identify necessary conditions (individual conditions that are always or almost always present with the positive outcome), we conducted a necessity/sufficiency analysis using fsQCA software in order to identify individual conditions with necessity consistency scores of 0.9 or higher (Ragin, 2008).

\section{Results}

\subsection{Outcomes}

\subsubsection{Outcomes 1: Current Latrine Coverage}

In both Cambodia and Ghana, most communities met the thresholds for high latrine coverage. In Cambodia, 9 of 13 communities had latrine coverage above the national threshold of $85 \%$ that is needed to qualify for ODF status. In Ghana, 11 of 15 communities had more than $75 \%$ latrine coverage at the time of our visits. Throughout this section, we refer to the nine communities in Cambodia and 11 communities in Ghana as having high coverage, though we analyzed their individual coverage as a continuous variable in the analysis. (For a full overview of each community, see Tables S5 and S6.)

Latrine types were very different between the two countries. In Cambodia, almost every household invested in high-quality pour-flush latrines (including cement or tiled slabs, handwashing facilities, and cement or brick super structures). Generally, households waited to build a latrine until they were able to afford a pour-flush latrine, and preferred open defecation over using dry pits, which were highly stigmatized. In contrast, due to the limited availability of construction materials in Northern Ghana, most latrines in the communities in this study were made of local materials (e.g., logs, mud, thatch, and occasionally cement for plastering) and were more susceptible to damage and collapse, especially during the rainy season. A few communities in Ghana had access to more robust plastic latrine slabs called "Digni-loos" through the W4H sanitation marketing program, but we found few of these in the communities selected for this study.

\subsubsection{Outcome 2: Consistent Latrine Use}

Consistent latrine use was more common in Ghana (9 out of 15 communities) than in Cambodia (3 out of 13 communities) (Tables S2 and S4). In Cambodia, communities with consistent latrine use generally had fewer households sharing latrines and had a perception of shame around OD. For example, one household explained "I cannot poop outside the latrine now. I feel too ashamed" (Case C6). In Ghana, households in communities with consistent latrine use typically rebuilt or repaired latrines when they collapsed or broke, felt comfortable sharing latrines with neighbors, and had awareness of potential sanctions for OD. One household noted, "If you see someone practicing OD, you report them and they will be fined" (Case G4).

The characteristics of households practicing open defecation varied between the two countries. In Cambodia, open defecation was most common among the poor or vulnerable, joint families sharing a single toilet, and those with new homes. In Ghana, open defecation was most common among households with collapsed or full latrines, and elderly or physically-disabled family members. Open defecation was also more common among pastoralists who lived on the outskirts of communities in Ghana. In both countries, all communities exhibiting consistent latrine use had at least $70 \%$ coverage at the time of our visit. 


\subsection{Condition Summaries}

Complete descriptions of how each condition was scored can be found in Table S1 for Cambodia and Table S3 for Ghana. Scores for each community can be found in Table S2 for Cambodia and Table S4 for Ghana.

\subsubsection{Leadership}

\subsubsection{Commune Engagement (Cambodia)}

The commune is the administrative level above the community (or village) in Cambodia and is the entry point for all community interventions. The commune served as the first point of entry for the CRSHIP program's interactions with communities, and implementing organizations often worked with communes to set targets for coverage increases in the communities under their jurisdiction. As a result, in most Cambodian communities, the elected Commune Chief was actively involved in supporting sanitation activities. Some communes used their budget to provide latrine materials or seek NGO support/subsidies to increase latrine coverage in their commune, particularly among late adopters. One community chief noted that the Commune Chief "helped those who are really desperate" (Case C13). In a few communities, Commune Chiefs or Commune Focal Points (commune-level officials selected by Commune Chiefs for monitoring CLTS and working with implementing organizations) were very engaged and also conducted frequent household visits alongside community leaders and NGOs. In some cases, households recalled being visited directly by the Commune Chief, who sometimes pressured or threatened them to build a latrine three to four times per month. One household admitted that they felt pressure from the commune, but could not afford the latrine: "After they pushed many times, I felt ashamed" (Case C1).

\subsubsection{Traditional Leaders}

We found that traditional leaders in both countries were well-respected, and implementers perceived their support as critical for sanitation activities. We considered the Village Chief the primary traditional leader in both countries, though deputy chiefs or other community elders sometimes also acted as traditional leaders. Traditional leaders were commonly involved in sanitation activities in most Cambodian and Ghanaian communities. However, the ways in which traditional leaders interacted with community members differed by country and community.

In Cambodia, while most traditional leaders were engaged in sanitation activities, we found that the level of pressure applied by traditional leaders to households varied by community. Traditional leaders in a few communities were not engaged at all, and applied no pressure on the households to construct latrines. In communities where leaders applied low levels of pressure, leaders held occasional community meetings and engaged in "casual chitchat" with community members during regular interactions; household visits were rare or infrequent. One household reported that the traditional leader "doesn't force anyone to build latrines but finds other ways to encourage households indirectly by bringing it up casually in conversation, talking about what their neighbors are doing, or asking questions about when they might build" (Case C6). In another community, "the [deputy] chief would blame them but in a funny way. He won't make them angry. He speaks politely. No one hates him" (Case C4). Conversely, communities that had leaders who applied a lot of pressure to households conducted frequent/repeated household visits, made threats to withhold marriage certificates or loans until latrine construction, dug dry latrine pits without household consent or involvement, and/or made threats to revoke subsidized latrine materials if latrines were not constructed within a certain period of time. A few households recalled coming home to find a dry pit built by the leaders while they were out, and one chief recalled, "we [went] to dig a pit for those [without] a latrine... whether or not the community members used it or not" (Case C1).

Conversely, traditional leaders in Ghana rarely engaged in intense household interaction themselves. Instead, traditional leaders acted as role models for the community, 
enforced by-laws (i.e., laws put in place and enforced by communities themselves rather than a higher authority), and selected and empowered natural leaders. In one community, a household noted that the chief "motivates us a lot, telling us not to relent in our efforts to keep the community ODF. He would normally say he is no longer strong to engage in digging or building, but he would usually promise to send a young man or two to assist if need be" (Case G2).

\subsubsection{Natural Leaders (Ghana)}

Natural leaders were community volunteers selected by the external CLTS facilitators in collaboration with the community during CLTS triggering activities, and were often seen as the "champions" of sanitation activities within the community. The use of natural leaders is a common implementation approach for CLTS programs [3]. Natural leaders in Ghana often supported latrine construction by conducting household visits post-triggering. Among communities with more engaged natural leaders, they also held regular meetings, visited households frequently, assisted with latrine construction, offered advice on cleaning and maintaining latrines, and enforced sanitation by-laws. Many natural leaders in Ghana reported that they supported households with technical advice: "Some will dig shallow or narrow, so I teach him to dig it deep and when they meet stone in the course, they don't know what to do, so I tell them to pour water on it to soften it so that they can dig deeper" (Case G1).

\subsubsection{Follow-Up}

3.2.2.1. Follow-Up by External Actors (NGOs in Cambodia and CLTS Facilitators in Ghana)

External actors were involved in follow-up activities post-triggering in both countries. In Cambodia, NGOs typically conducted follow-up alongside traditional leaders. In Ghana, CLTS facilitators were responsible for post-triggering follow-up alongside natural leaders and were either district government officials (in RING communities) or NGO staff (in W4H communities). In Cambodia, all communities had been simultaneously exposed to CLTS and multiple other sanitation interventions by different actors. In comparison, communities in Ghana received fewer sanitation programs; only one of our study communities in Ghana had been exposed to another sanitation intervention in addition to CLTS.

In Cambodian communities with high follow-up intensity, NGOs conducted frequent household visits and meetings. In some cases, this was met with acceptance and gratitude for the NGO's hard work: the NGO "was very active in following up with community members and the way they taught was also sensitive. If there is no action plan from NGOs, [community leaders] would be less active" (Case C11). In other cases, frequent visits created NGO fatigue: "When we [the NGO] visited again and again, they felt bored with us" (Case C12). One household reported that frequent follow-up discouraged participation in meetings, "When I didn't have the latrine, they invited me all the time. I felt ashamed and didn't want to go" (Case C1). In communities with less external follow-up, community meetings took place, but households were unlikely to remember many household visits, the names of NGOs, or specific events related to sanitation.

In Ghana, almost all communities received some form of external follow-up from a CLTS facilitator in the weeks post-triggering. In most communities, the CLTS facilitator held multiple community meetings, conducted household visits, and trained natural leaders on how to construct and maintain latrines. Two communities reported that the CLTS facilitator went above and beyond typical follow-up requirements by staying in the community during the first few weeks of triggering, training natural leaders, visiting households, and supporting latrine construction. For example, "the facilitators slept in the community for four days immediately after triggering and educated the households on the usage of the latrines" (Case G4).

\subsubsection{Post-ODF Follow-Up by Internal Actors (Ghana)}

High follow-up post-ODF occurred among one-third of communities where natural leaders or community chiefs continued to support households after communities achieved ODF. In these cases, they assisted with latrine construction or repairs and held weekly 
sanitation activities. For example, natural leaders "go around the whole community to inform [households] about sanitation. They also go around to inspect toilets and make sure they are washed and cleaned" (Case G2). In communities with low post-ODF follow-up, community chiefs or natural leaders were no longer active in sanitation activities. One household noted that, "it has been a year since the leaders visited households" (Case G14).

\subsubsection{Pro Poor and Financial Support}

\subsubsection{Financial Support (Cambodia)}

In Cambodia, subsidies and loans existed in almost every community but with varying coverage, ranging from $1 \%$ to $52 \%$ of households. Government programs, local NGOs, private sector actors, or international NGOs initiated these programs, which generally operated separately from the implementer CRSHIP, and provided subsidies either before or after the triggering event, or both. Most subsidy programs documented in this study did not solely target poor or vulnerable households (which we examined as a separate condition, see Section 3.2.3.3). The level of support varied: some programs offered rebates to cover partial costs, some provided construction materials for the substructure only, while others subsidized $100 \%$ of the cost of toilet installation. Three communities demonstrated high utilization of subsidies and loans; in one community "fifty households received a subsidized latrine (free sub-structure or 50\% subsidized sub-structure)" and "up to 50\% of community members borrowed money to build latrines" (Case C6). One-third of communities demonstrated utilization of loans but low utilization of subsidies; another third of communities had low utilization of any type of financial support (i.e., loans and/or subsidies).

\subsubsection{Subsidies before Triggering (Cambodia)}

In just over half of the communities, some form of subsidy program was implemented before CLTS activities began in the community. Some of these communities received latrine materials through previous sanitation programs implemented by UNICEF, but most communities received them from smaller, local NGOs that were not associated with any government programs or CRSHIP. These small NGOs worked on sanitation in addition to other community development projects, and typically worked with local suppliers to provide latrine substructure materials at a reduced cost (50\% of normal price) or free. In some cases, but not always, the subsidies were specifically targeted to poor households. Gathering information on these programs was challenging because most community members could not recall details of the programs.

\subsubsection{Pro-Poor Support/Internal Support}

Support to poor and vulnerable households took on different forms in the two countries. In Cambodia, the commune or NGOs provided financial or material subsidies, whereas in Ghana communities activated internal support mechanisms (i.e., neighbors helping with construction) to assist poor and vulnerable households. There was minimal evidence of internal support in Cambodia, potentially due to latrine construction being predominantly procured through paid masonry services (compared to local materials in Ghana).

Few Cambodian communities had high intentional pro-poor support, "I identified families that did not have enough money to pay for a latrine and I would report this to the Commune Councilmember on Women and Children ... who would include this in the commune budget so that these households did not have to pay for the latrine" (Case C12). Even in communities with pro-poor support, we found that poor households struggled to complete latrines, particularly when hardware subsidies only covered the substructure. In a few communities, some poor households received support but it was not intentionally targeted to poor households. In most communities, poor households did not receive intentional or targeted pro-poor support, and in cases where communes provided latrine materials to households, this support was typically a strategy to "close the gap", or as the final effort to reach $85 \%$ coverage in the community. 
In Ghana, we found that many communities provided internal support in the form of neighbors helping with construction or allowing neighbors to share latrines. One natural leader mentioned, "[We] identify poor [households] and go with youth to dig pits for them when they get permission from the chief" (Case G1). However, many community members in Ghana rarely acknowledged any of their neighbors as poor or vulnerable, stating that "we are all poor," or that there is no excuse for not building a latrine given that the materials are "free" (multiple cases). Some communities had little evidence of internal support.

\subsubsection{Women in Sanitation (Ghana)}

In Ghana, CLTS facilitators primarily targeted women to convince households to construct latrines. In communities where women's engagement was high, women played a key role in maintaining latrines over time and female natural leaders were active in sanitation-related activities. One natural leader stated, "Women are the right people to engage in the community to improve sanitation because of their primary role as gatekeepers of households" (Case G3). A female respondent mentioned that "We the women are in charge of sanitation in our homes, we take care of the children, the aged and the sick" (Case G6). We also found that some women persuaded their husbands to build latrines; one interviewee noted, "Most of the women told their husbands that they would leave them if they did not put up latrines. They said they did not like people to watch their nakedness as they defecate openly" (Case G5). Women and men both reported that women had greater needs for a latrine because of privacy and safety. We could not analyze the role of women in Cambodia due to insufficient variability: women were always involved in decision-making at the household level, but never involved as traditional leaders or commune leaders.

\subsection{Pathway Analysis}

\subsubsection{Latrine Coverage in Cambodia}

Our QCA analysis identified two pathways that characterized communities with high latrine coverage in Cambodia, with an overall solution consistency of 0.93 (Figure 2). These two pathways cover six out of nine communities where current coverage was $85 \%$ or higher. In both pathways, communities received a combination of low NGO follow-up post-triggering, low pro-poor support, and low financial support. In addition to these three conditions, our study communities with high coverage also had one of two conditions: either traditional leaders who applied very little pressure on households to construct latrines (Pathway 1a, five cases), or commune-level officials who were highly engaged in community activities (Pathway 1b, four cases). There is overlap in the communities covered by the two pathways; three cases had both community leaders who applied low pressure and highly engaged commune officials. 


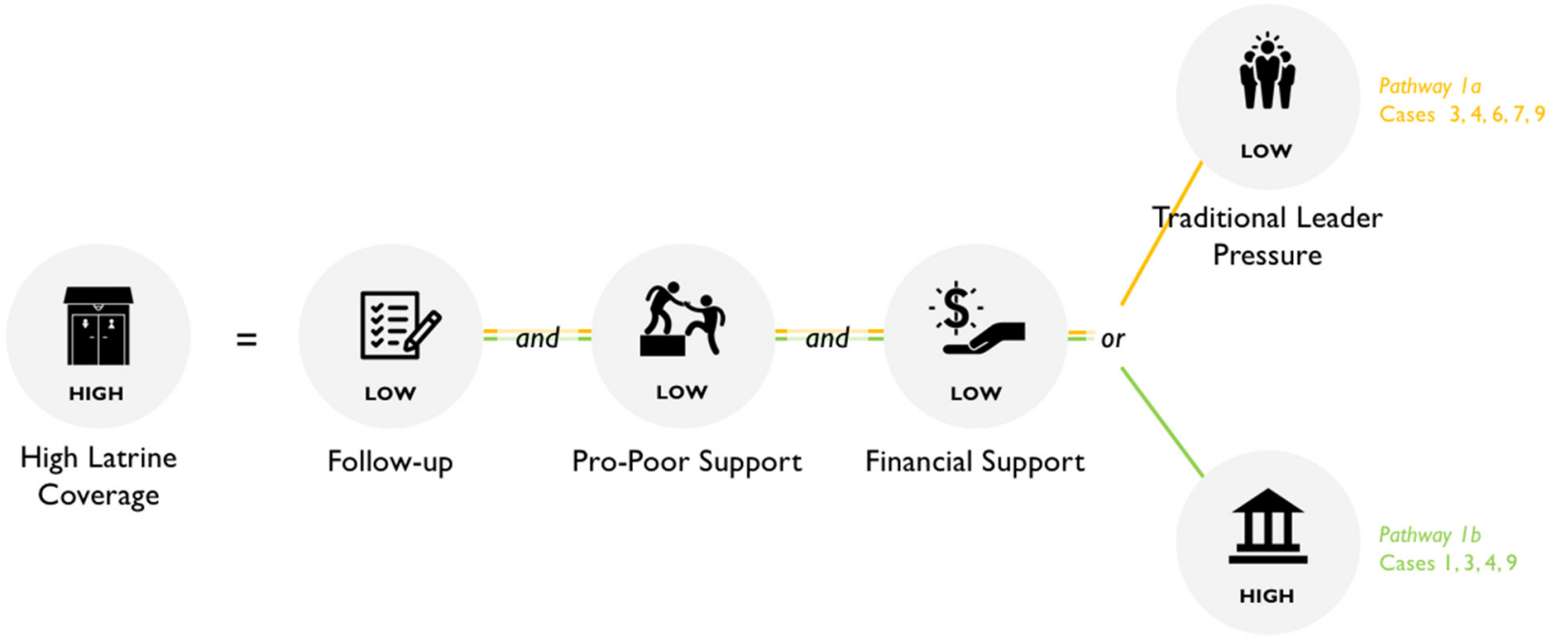

Commune Engagement

Figure 2. Pathways for high latrine coverage in Cambodia. Using fsQCA, we identified two pathways for achieving the outcome of high latrine coverage in Cambodia. Both pathways included the conditions of low follow-up, low pro-poor support, and low financial support. Pathway 1a also included low pressure from traditional leaders, and pathway $1 \mathrm{~b}$ included high commune engagement.

\subsubsection{Latrine Coverage in Ghana}

We identified two pathways characterizing seven out of 11 communities with high latrine coverage in Ghana (solution consistency $=1$, solution coverage $=0.55$ ) (Figure 3). All pathways included the combination of engaged natural leaders post-triggering, high internal follow-up post-ODF (by natural or traditional leaders), and high internal support (i.e., neighbors helping neighbors to construct latrines). Pathway $2 \mathrm{a}$ also included engaged traditional leaders and high follow-up by CLTS facilitators. Pathway $2 \mathrm{~b}$ did not include active traditional leaders, but did incorporate women that were highly engaged in sanitation (two cases).

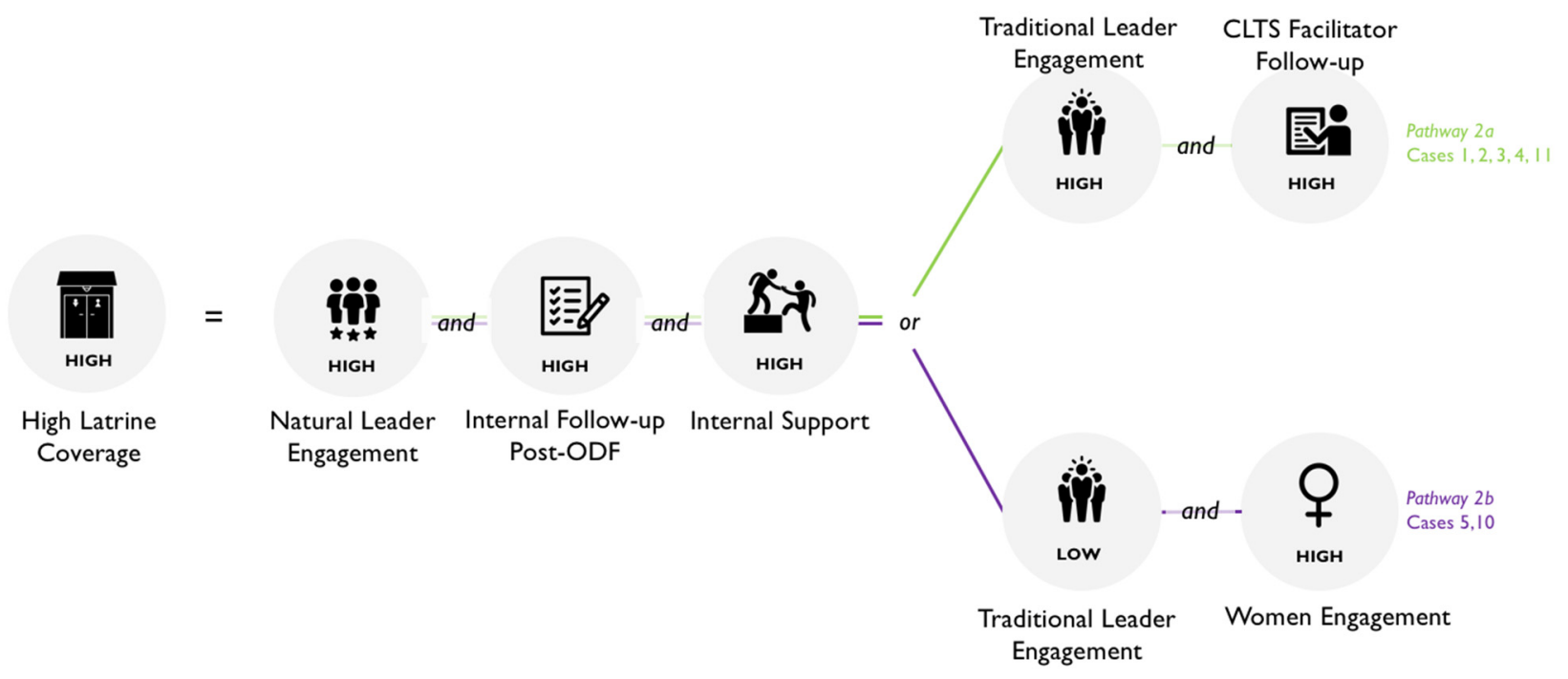

Figure 3. Pathways for high latrine coverage in Ghana. Using fsQCA, we identified two pathways for achieving the outcome of high latrine coverage in Ghana. Both pathways included the conditions of high natural leader engagement, high internal follow-up post ODF, and high internal support. Pathway 2a also included engaged traditional leaders and high CLTS facilitator follow-up, while pathway $2 \mathrm{~b}$ included the combination of inactive traditional leaders and high engagement of women. 


\subsubsection{Inconsistent Latrine Use in Cambodia}

We were unable to analyze pathways for consistent latrine use because we did not have enough cases with consistent use in the sample; however, we were able to examine the inverse outcome: inconsistent use. We identified three pathways characterizing 8 out of 10 communities that exhibited inconsistent latrine use in Cambodia (solution consistency $=0.93$, solution coverage $=0.68$ ) (Figure 4). High commune engagement in community-level sanitation activities appeared in all three pathways for inconsistent latrine use. Pathway 3a also included low NGO follow-up, low financial support and low pro-poor support (three cases). In contrast, pathways $3 \mathrm{~b}$ and $3 \mathrm{c}$ included high NGO follow-up, high financial support, and high pro-poor support (five cases). Pathway $3 \mathrm{~b}$ included intense pressure applied by traditional leaders (four cases), such as the threat to revoke subsidies if households were unable to complete construction of their latrines in a certain period of time. Pathway $3 \mathrm{c}$ also included subsidies before triggering (four cases). There was overlap in the communities covered by pathways $3 b$ and 3c; three cases had both subsidies before triggering and aggressive strategies used by community leaders.

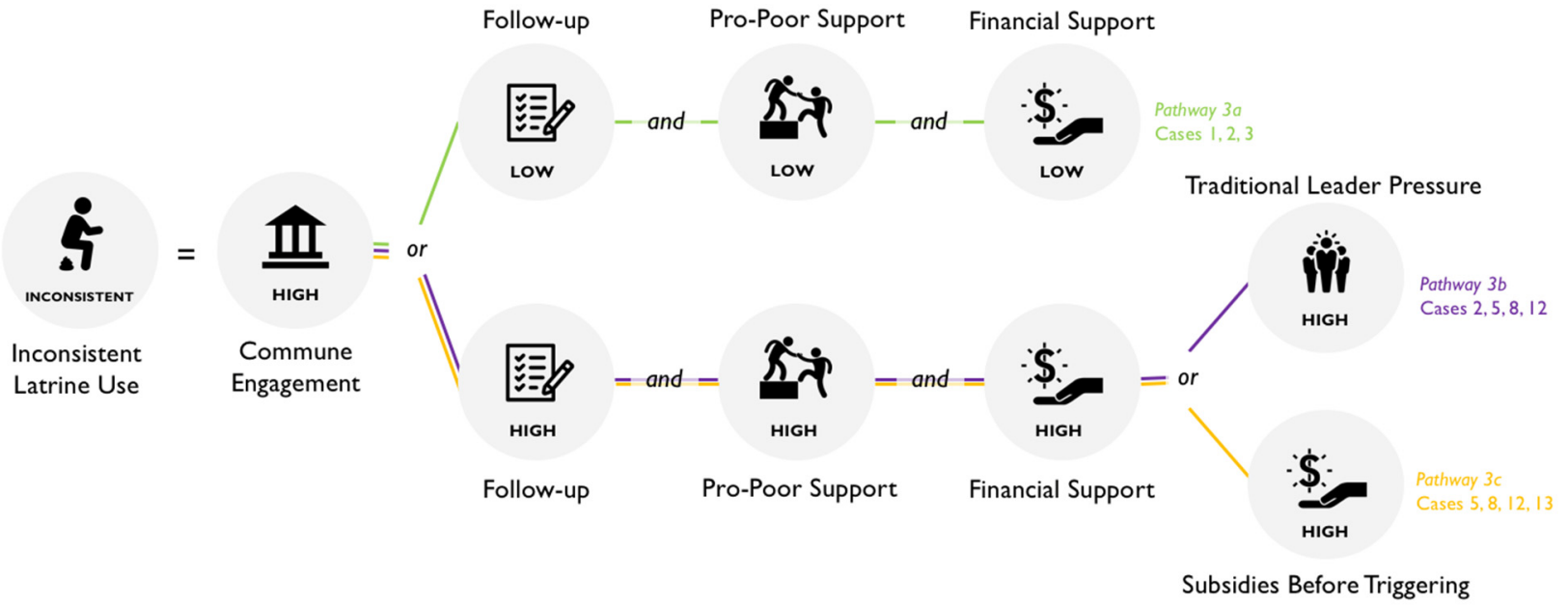

Figure 4. Pathway for inconsistent latrine use in Cambodia. Using fsQCA, we identified three pathways for achieving the outcome of inconsistent latrine use in Cambodia. All pathways included the condition of high commune engagement. Pathway 3a also included low follow-up, low pro-poor support, and low financial support. Pathways $3 \mathrm{~b}$ and $3 \mathrm{c}$ both included the conditions of high follow-up, high pro-poor support, high financial support, and either high traditional leader pressure (3b) or subsidies before triggering (3c).

\subsubsection{Consistent Latrine Use in Ghana}

We found three pathways characterizing 6 out of 9 communities with consistent latrine use in Ghana (solution consistency $=1$, solution coverage $=0.66$ ) (Figure 5). High internal support was considered a necessary condition according to QCA necessity/sufficiency analysis: all cases with consistent latrine use had high internal support (consistency $=0.93$ ). All of these pathways also included active natural leaders and active internal follow-up post-ODF. In all solutions, there was some combination of active CLTS facilitators, traditional leaders, and women: Pathway 4a included active CLTS facilitators and traditional leaders (five cases), pathway $4 \mathrm{~b}$ included active CLTS facilitators and engaged women (four cases), and pathway 4c included active traditional leaders and engaged women (four cases). 


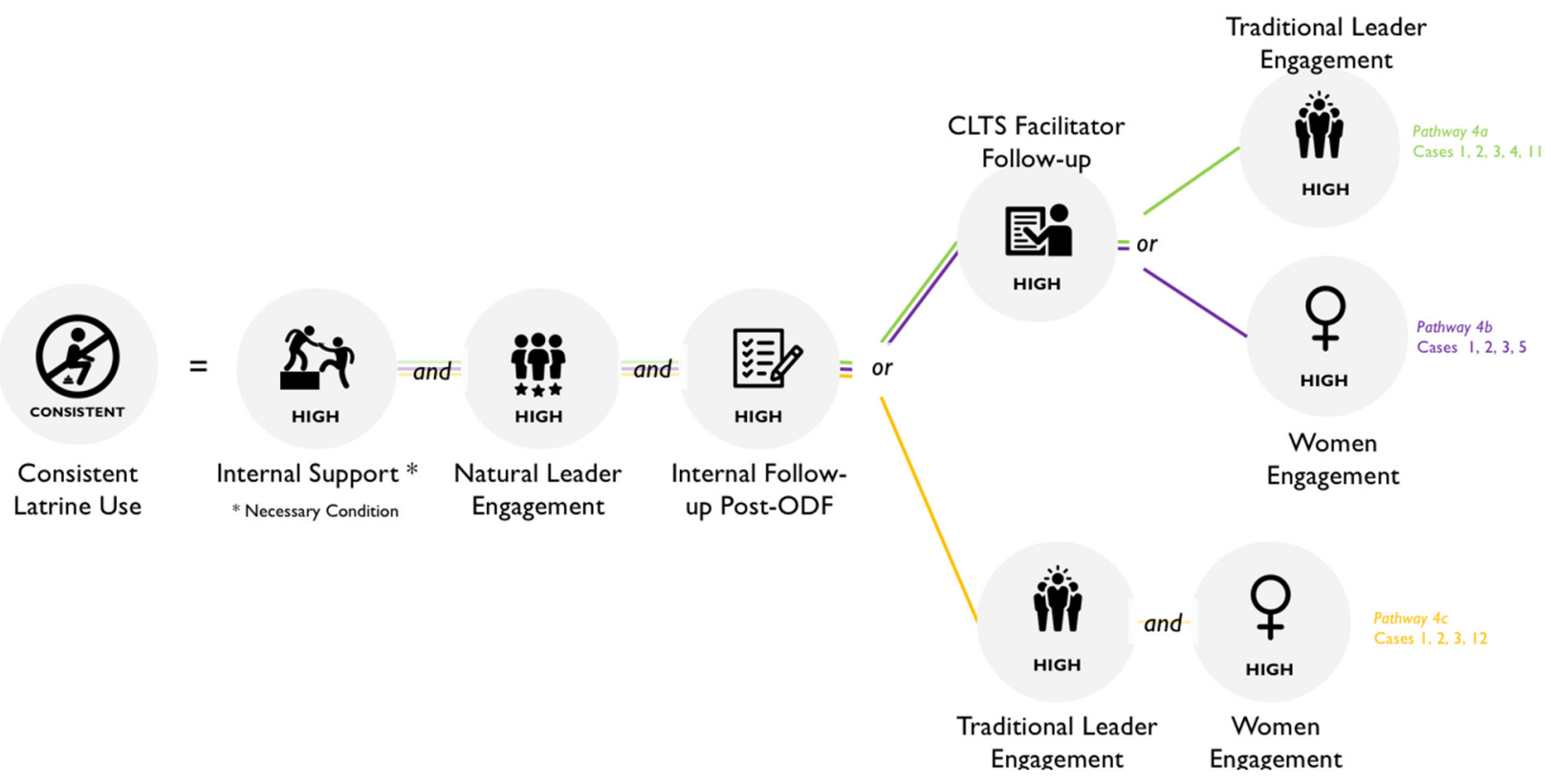

Figure 5. Pathways and conditions sufficient for consistent latrine use in Ghana. fsQCA identified three pathways for achieving the outcome of consistent latrine use in Ghana. All pathways included the conditions of high internal support, high natural leader engagement, and high internal follow-up post-ODF. Internal support was also considered a necessary condition according to the necessity/sufficiency analysis, meaning all cases with consistent latrine use had high internal support. In addition to these conditions, pathways $4 \mathrm{a}$ and $4 \mathrm{~b}$ both included high follow-up by CLTS facilitators, and either high engagement by traditional leaders (4a) or high engagement of women (4b); pathway 4c included both active traditional leaders and engaged women.

\section{Discussion}

Our study goals were to understand and compare the local conditions that influence sustained latrine coverage and consistent use in communities that participated in CTLS programs in Cambodia and Ghana. We analyzed conditions under three categories of interest: (i) engagement of community leaders, (ii) post-triggering and post-ODF follow-up, and (iii) financial and pro-poor support. By using fsQCA, we identified how combinations of conditions influenced outcomes, allowing us to better understand how the actors at the community level worked in concert. By comparing the countries, we aimed to draw conclusions on how mechanisms for sanitation uptake vary in different settings.

\subsection{Conditions Influencing High Latrine Coverage in Cambodia and Ghana}

The differences between the pathways for high latrine coverage in Cambodia and Ghana highlight differences in community dynamics and context between the two countries, and the effects of these differences on CLTS program outcomes. In Cambodia, communities with high latrine coverage generally received lower levels of financial or pro-poor support, lower levels of follow-up by external actors after triggering, and households received less pressure from traditional leaders. The combination of these conditions resulted in a "light touch" by most actors, which is in contrast with expectations for successful CLTS implementation [9]. In Ghana, by contrast, we found that both traditional and natural leaders played key roles post-triggering and post-ODF among communities with high coverage. In addition to high engagement from leaders, high coverage communities in Ghana typically had high internal support (i.e., neighbors helping neighbors with latrine construction) and high follow-up by CLTS facilitators post-triggering.

External actors were more important in Ghana than in Cambodia because they provided helpful technical skills for latrine construction. Our research indicates that CLTS facilitators' post-triggering support can have lasting effects post-ODF to ensure the sustainability of latrine coverage in Ghana. This is consistent with a study of CLTS implementation in Ghana which found that every additional follow-up visit by a CLTS facilitator was associ- 
ated with an increase in latrine coverage [15]; technical support has been found to be critical for sanitation success in other studies [4,44]. In Cambodia, where markets are relatively accessible and communities experienced multiple sanitation marketing efforts, it is possible that non-poor households were less reliant on NGOs for obtaining latrine materials or for latrine construction. In fact, the sheer number of sanitation actors in Cambodia may have resulted in "intervention fatigue" at the community level, and could have been detrimental when combined with aggressive tactics by leaders.

Support to poor households took on different forms in Cambodia and Ghana, reflecting the different community dynamics in each country. In Cambodia, support to poor households was generally low among high coverage communities. In addition, we did not find evidence of internal community support for sanitation improvement, which is in line with a previous study that found minimal evidence of bridging social capital (i.e., the interest of community members to form groups to address shared needs, which is a key component of collective efficacy) with regards to sanitation activities among communities in Cambodia [45]. Yet, even without internal support, Cambodian communities had relatively high levels of latrine coverage many years post-ODF. In addition to good access to markets, Cambodia has experienced sustained economic growth in the time period since CLTS began which may be contributing to increased incomes and willingness to pay for high-quality latrines at the household level; the average GDP growth in Cambodia from 2011-2017 was 7.13\% [46]. Our complementary studies found that higher literacy, which is often a proxy for economic growth or household wealth, was associated with sanitation gains [8]. In Ghana study communities, external subsidies were nonexistent, and our interviews revealed that although most communities rarely acknowledged differences in household wealth, there were often internal support mechanisms activated to complete latrine construction for all households. These findings from Ghana are in line with previous studies that found that ODF achievement is linked to internal support mechanisms targeting all community members in Indonesia [47].

One condition that was similar among high coverage communities in both Cambodia and Ghana was the role of community leaders-but only when those leaders used similar strategies. Traditional leaders in Cambodia were more successful when they took a more casual approach to persuading households to construct latrines, rather than using aggressive tactics. The casual strategies employed by traditional leaders in Cambodia's higher-achieving communities closely resembled the strengths of natural leaders described in studies in other contexts, such as their abilities to draw upon daily experiences [48] and their abilities to relate to community members [49]. Previous research in Ghana also found that strong natural leaders were fundamental for achieving and sustaining ODF [14,15].

An exception to the "light touch" solution among high coverage communities in Cambodia is the role of the commune, which was typically very engaged in high coverage communities. Communes were engaged by NGOs and District or Province-level officials to encourage communities to construct latrines in order to meet targets under the CRSHIP program. As a result, it is not surprising that the commune played a critical role in increasing latrine coverage. Local government officials in Ghana did not play a similar role as commune officials in Cambodia, but arguably the CLTS facilitators may have acted in a similar capacity as an external actor associated with local government offices.

\subsection{Conditions Influencing Latrine Use in Cambodia and Ghana}

The pathways for high latrine coverage and consistent use in Ghana were similar to one another, and reflected the characteristics of a true community-led effort [3]. In Cambodia, we were only able to assess inconsistent latrine use, and the results were more nuanced than those for high coverage. Comparing the two countries, we again found many differences that can be explained both by context and the different strategies used by local leaders.

In Cambodia, some cases had relatively high coverage but a subset of households practiced inconsistent latrine use or always practiced open defecation. Inconsistent use 
occurred in two scenarios, both of which included active commune engagement. The first set of cases was characterized by low follow-up, low pro-poor support, and low financial support (Pathway 3a, Figure 4). It is possible that excessive pressure by commune officials on traditional leaders and households may have had negative impacts on consistent use, even though coverage was high. Given the preference for high-quality latrines in Cambodia, most households preferred to wait until they had enough money to build the latrine of their preference. When pressured to construct a latrine quickly using a design that did not meet their preference, households may have been less likely to use the latrine. Such findings are consistent with previous studies which found that sustainability is more common among programs focused on behavior change rather than forceful, rapid latrine construction [26,50-54]. Pathways $3 \mathrm{~b}$ and $3 \mathrm{c}$ (Figure 4) indicated inconsistent latrine use among communities that experienced intense follow-up and engagement from both internal and external actors, which, in some cases, began prior to CLTS programming. These pathways included the combination of high follow-up post-triggering, high pro-poor support, and high financial support combined with either aggressive leader strategies or subsidies before triggering. These results are also consistent with that of other studies which have found that using fear or threats to force people to build latrines can lead to inconsistent use [26,52], or that sanctions (or threat of sanctions) might disproportionately affect the poor [55].

In Ghana, we found that communities that exhibited consistent latrine use had traditional leaders or CLTS facilitators that supported the work of natural leaders. Households reported that the enforcement of sanctions/by-laws by traditional leaders and the establishment of consequences were critical for ensuring latrine coverage and use; sanctions/bylaws were generally widely accepted by community members. This result in Ghana contrasted our findings from Cambodia, where sanctions and aggressive strategies had negative effects. There is evidence indicating that by-laws designed in a participatory fashion can be effective [56], whereas top-down sanctions, such as the threats to refuse marriage licenses or loan applications by commune officials in Cambodia, may be less effective [57]. Furthermore, our finding that participation in community events decreased when households in Cambodia felt shame through frequent visits and pressure from community leaders is consistent with previous research that concluded that shaming techniques commonly used during CLTS triggering could be counter-productive in Cambodia [19].

In Ghana, active leaders and regular follow-up combined with internal support were characteristics of most communities with consistent latrine use. This again contrasted with the findings in Cambodia, where more engagement from leaders and NGOs resulted in inconsistent use. A key difference between the two countries is the presence of internal support, which could be an important factor for ensuring that leader and NGO strategies are effective. We found no evidence of internal support in Cambodia, while internal support appeared as a necessary condition for consistent latrine use in Ghana. Similarly, another study found that social identification (i.e., the extent to which individuals believe they belong to a group or community) was significantly associated with ODF achievement in Ghana [58].

In addition, natural leaders in high-performing communities in Ghana continued post-ODF follow-up, but post-ODF follow-up was rare in Cambodia. While communities in Cambodia may have received intense follow-up leading up to ODF certification, it rarely continued post-ODF. However, continued activity by natural leaders could be considered essential in Ghana, where latrines made of local materials require constant maintenance and rebuilding. This follow-up may not be necessary to maintain latrine coverage in Cambodia, where high-quality latrines are relatively easy to maintain. However, these results demonstrate that this continued support may have an impact on latrine use.

\subsection{Role of Women}

In Ghana, the pathways that determined sanitation outcomes suggest an interesting dynamic between the roles of traditional leaders, CLTS facilitators, and women: women were often engaged in cases where either traditional leaders or CLTS facilitators were 
absent, both in their role in the household and as natural leaders. This suggests that women have the potential to replace the role of traditional leaders (who were all male) in encouraging continued high latrine coverage and use. Other studies have demonstrated that female-headed households or households where women have economic decisionmaking power are more likely to have latrines [16,59] and less likely to return to open defecation after ODF certification [60].

However, higher women's engagement should not necessarily be interpreted as an indication of empowerment, but may be a result of upholding existing gender roles. Previous studies have found that women were often targeted during triggering and followup activities because they were seen as being responsible for household tasks, especially cleaning and maintaining latrines [61-65]. Another study in Uganda found that while women considered themselves leaders in implementing CLTS activities and achieving ODF, men still believed they were the "monitors" and "supervisors" of sanitation [66]. Finally, some households without latrines in study communities in Ghana included female-headed households that did not have the financial or physical resources to construct latrines, emphasizing that vulnerability and poverty are still barriers to latrine adoption.

\subsection{Implications for Future Programming and Research}

These findings have implications for future sanitation programs in Cambodia and Ghana. In Cambodia, the focus should shift away from imposing top-down sanitation targets that encourage community leaders and NGOs to employ aggressive strategies, and instead, equip community leaders with strategies to maintain latrine use and emphasize latrine sharing as a temporary rather than permanent solution. In Cambodia, where construction materials are relatively accessible to non-poor households and internal support mechanisms are rare, there is a need to provide targeted support to poor and vulnerable households soon after triggering, rather than through aggressive strategies in the final stages before ODF certification. In Ghana, with limited access to durable latrine materials, it is critical to support latrine construction and repair in order to sustain outcomes after external interventions end. Some communities may be able to provide this support internally (i.e., neighbors helping neighbors), though others may require more encouragement from CLTS facilitators and natural leaders. In addition, this study provides further evidence that investments in natural leaders can result in sustained sanitation outcomes.

Our results from Ghana demonstrate that active natural leaders are successful when combined with multiple other conditions (high internal support, high follow-up by CLTS facilitators, and active traditional leaders). In other words, active natural leaders alone are not enough for communities to maintain their ODF status over time-support is needed from a variety of internal and external actors. In both countries, we found that most conditions linked to post-ODF coverage and use (either positively or negatively) were results of activities and strategies that were implemented in the time between triggering and ODF achievement; therefore, implementers should plan for sustainability from the outset of implementation.

Therefore, marked differences in responses to sanitation programming between Cambodia and Ghana indicate that rural communities do not react equally to sanitation behavior change strategies. These findings are corroborated by our complementary quantitative study that found that predictors of CLTS performance were largely contextual and varied between geographies, and by a previous study that found that initial community dynamics such as trust and social capital can alter the effectiveness of CLTS programming [8,67]. Understanding and accounting for nuanced community reactions to sanitation intervention practices are therefore critical for fostering long-term sustainability beyond short-term achievements. For example, conducting a contextual analysis during pre-triggering may help implementers to tailor implementation strategies to specific community perspectives and contexts. 


\subsection{Study Limitations}

This study is not without limitations. First, although QCA attempts to understand cause and effect, we cannot establish rigorous causality. For example, high latrine coverage may be found in communities with a lack of external follow-up or financial/pro-poor support, but it is possible that these communities did not receive additional follow-up or support because they were able to increase coverage due to other confounding factors, such as higher income levels, which we were unable to measure. Second, QCA methodology only allows for a small number of conditions to be included in the analysis (typically <10) [37]; there may be other factors influencing outcomes that we did not examine. This study prioritized factors that implementers have the ability to influence. Third, latrine coverage data in this study were estimates made by local researchers based on multiple household and community leader interviews, not by visiting every household in each community. Fourth, our unit of analysis was the community; therefore, each outcome and condition was assessed according to the prevailing trend across the community, despite the reality of heterogeneity within communities. Fifth, the abundance of sanitation programs in Cambodia made it difficult to assess the activities and strategies of CLTS programs alone; all study communities in Cambodia received other sanitation programs (including sanitation marketing, hardware subsidies, loans, and microfinance), many of which used behavior change approaches similar to CLTS triggering. Six, we observed communities at least two years post-implementation; we were not able to verify conditions prior to program implementation. Lastly, the research team completed data collection in Ghana at the beginning of the rainy season, which may have contributed to lower than average latrine coverage due to a higher probability of latrine collapse.

\section{Conclusions}

This study provided an opportunity to examine the role of community-level dynamics in sustaining sanitation outcomes in two countries with very different contexts. In Cambodia, although latrine coverage remains high in many communities, our QCA results indicated that, contrary to expectations, aggressive strategies from leaders, increased follow-up, and access to subsidies did not lead to consistent latrine use. However, these findings must be considered alongside Cambodia's unique context, particularly the sheer number of sanitation interventions, access to markets, strong preference for high-quality latrines, and economic growth. In Ghana, in line with previous evidence and expectations for CLTS, our results emphasize the importance of natural leaders, particularly when they are supported by traditional leaders and external facilitators, and the value of strong internal support mechanisms for sustained sanitation outcomes. The role of women emerged in Ghana as an important factor in sustaining latrine coverage and use, both in their role in influencing household decisions, and as natural leaders within the community. Regardless of context, as a community-based approach, CLTS requires continuous engagement of both local leaders and community members, with whom the capacity for sustaining outcomes ultimately resides. In addition to monitoring latrine coverage targets, assessing community contexts prior to and during implementation will help implementers assess the likelihood of sustainability, and reinforce internal mechanisms for success before programs conclude. Future research could also explore opportunities for tailoring implementation strategies to specific community contexts.

Supplementary Materials: The following are available online at https://www.mdpi.com/article/ 10.3390/su13105440/s1, Table S1: Complete Scoring Rubric Cambodia; Table S2: QCA Scores for Cambodia, Table S3: Complete Scoring Rubric Ghana; Table S4: QCA Scores for Ghana; Table S5: Overview of Cambodia study communities; Table S6: Overview of Ghana Communities; Figure S1: Selection of conditions for Cambodia; Figure S2: Selection of conditions for Ghana.

Author Contributions: Conceptualization, J.T., R.P., V.Z., R.K., and C.D.; methodology, J.T., R.P. and V.Z.; software, J.T.; validation, R.P. and V.Z.; formal analysis, J.T.; investigation, J.T., V.Z. and R.P.; resources, R.K.; writing—original draft preparation, J.T.; writing-review and editing, C.D., R.K., 
R.P., V.Z.; visualization, J.T.; supervision, R.K. and R.P.; project administration, J.T. and R.P.; funding acquisition, R.K. All authors have read and agreed to the published version of the manuscript.

Funding: This work was conducted under the United States Agency for International Development's (USAID) Water, Sanitation and Hygiene Partnerships and Learning for Sustainability project under Task Order number AID-OAA-TO-16-00016 of the Water and Development Indefinite Delivery Indefinite Quantity Contract, contract number AID-OAA-I-14-00068. The authors alone are responsible for the views expressed in this publication and they do not necessarily represent the decisions or policies of USAID.

Data Availability Statement: The data presented in this study are available in the Supplementary Materials.

Acknowledgments: We gratefully acknowledge the communities, households, and enumerators that made this study possible. We thank the following individuals for their help at various stages of data analysis and manuscript preparation: Elizabeth Jordan (USAID), Jesse Shapiro (USAID), Morris Israel (Tetra Tech), Moung Vandy and the team at iDE Cambodia, Prince Antwi-Agyei (Nhance Development Partners), Bashiru Yachori (The Aquaya Institute), Shamsudini Amidu (The Aquaya Institute), Sale Rhodes (The Aquaya Institute), Clara MacLeod (The Aquaya Institute), and Jeff Albert (The Aquaya Institute). This work would not be possible without the support and collaboration of our partners, Global Communities (Ghana) and CRSHIP (Cambodia).

Conflicts of Interest: The authors declare no conflict of interest.

\section{References}

1. WHO/UNICEF JMP. Progress on Household Drinking Water, Sanitation and Hygiene 2000-2017: Special Focus on Inequalities; UNICEF: New York, NY, USA, 2019.

2. Zuin, V.; Delaire, C.; Peletz, R.; Cock-Esteb, A.; Khush, R.; Albert, J. Policy Diffusion in the Rural Sanitation Sector: Lessons from Community-Led Total Sanitation (CLTS). World Dev. 2019, 124, 104643. [CrossRef]

3. Kar, K.; Chambers, R. Handbook on Community-Led Total Sanitation; Plan International: Brighton, UK, 2008 ; Volume 44.

4. Venkataramanan, V.; Crocker, J.; Karon, A.; Bartram, J. Community-Led Total Sanitation: A Mixed-Methods Systematic Review of Evidence and Its Quality. Environ. Health Perspect. 2018, 126, 17. [CrossRef]

5. WaterAid; UNICEF; Plan International. Rethinking Rural Sanitation Approaches; The Water Institute at UNC: Chapel Hill, NC, USA, 2017

6. Whittington, D.; Radin, M.; Jeuland, M. Evidence-based policy analysis? The strange case of the randomized controlled trials of community-led total sanitation. Oxford Rev. Econ. Policy. 2020, 36, 191-221. [CrossRef]

7. USAID. An Examination of CLTS's Contributions Toward Universal Sanitation; USAID: Washington, DC, USA, 2018.

8. Stuart, K.; Peletz, R.; Albert, J.; Khush, R.; Delaire, C. Where Does CLTS Work Best? Quantifying Predictors of CLTS Performance in Four Countries. Environ. Sci. Technol. 2021. [CrossRef] [PubMed]

9. Cavill, S.; Chambers, R.; Vernon, N. Frontiers of CLTS: Innovations and Insights; Institute of Development Studies: Brighton, UK, 2015.

10. Mukherjee, N.; Robiarto, A.; Saputra, E.; Wartono, D. Achieving and Sustaining Open Defecation Free Communities: Learning from East Java; Water Sanitation Program, World Bank: Washington, DC, USA, 2012.

11. UNICEF. Evaluation of the WASH Sector Strategy 'Community Approaches to Total Sanitation' (CATS); UNICEF: New York, NY, USA, 2014.

12. Lawrence, J.J.; Yeboah-Antwi, K.; Biemba, G.; Ram, P.K.; Osbert, N.; Sabin, L.L.; Hamer, D.H. Beliefs, Behaviors, and Perceptions of Community-Led Total Sanitation and Their Relation to Improved Sanitation in Rural Zambia. Am. J. Trop. Med. Hyg. 2016, 94, 553-562. [CrossRef]

13. Robinson, A. Final Evaluation: Pan African CLTS Program 2010-2015; Plan Netherlands: Amsterdam, The Netherlands, 2016.

14. Crocker, J.; Shields, K.F.; Venkataramanan, V.; Saywell, D.; Bartram, J. Building capacity for water, sanitation, and hygiene programming: Training evaluation theory applied to CLTS management training in Kenya. Soc. Sci. Med. 2016, 166, 66-76. [CrossRef]

15. Harter, M.; Lilje, J.; Mosler, H.J. Role of Implementation Factors for the Success of Community-Led Total Sanitation on Latrine Coverage. A Case Study from Rural Ghana. Environ. Sci. Technol. 2019, 53, 5466-5472. [CrossRef]

16. Kullmann, C.; Ahmed, R.; Hanchett, S.; Krieger, L.; Kahn, M.H. Long-Term Sustainability of Improved Sanitation in Rural Bangladesh; Water Sanitation Program, World Bank: Washington, DC, USA, 2011.

17. Tyndale-Biscoe, P.; Bond, M.; Kidd, R. ODF Sustainability Study; Plan International: Brighton, UK, 2013.

18. Gertler, P.J.; Shah, M.; Alzua, M.L.; Cameron, L.A.; Martinez, S.; Patil, S.R. How Does Health Promotion Work? Evidence from The Dirty Business of Eliminating Open Defecation; National Bureau of Economic Research: Cambridge, MA, USA, 2015. [CrossRef]

19. Bateman, M.; Engel, S. To shame or not to shame — that is the sanitation question. Dev. Policy Rev. 2018, 36, 155-173. [CrossRef] 
20. Alzua, M.L.; Pickering, A.J.; Djebbari, H.; Lopez, C.; Cardenas, J.C.; Lopera, M.A.; Osbert, N.; Coulibaly, M. Impact Evaluation of Community-Led Total Sanitation (CLTS) in Rural Mali; CEDLAS, Working Papers 0191, CEDLAS; Universidad Nacional de La Plata: La Plata, Argentina, 2015.

21. Cameron, L.A.; Shah, M. Scaling Up Sanitation: Evidence from an RCT in Indonesia; Abdul Latif Jameel Poverty Action Lab: Cambridge, MA, USA, 2017.

22. Harvey, P.A. Zero subsidy strategies for accelerating access to rural water and sanitation services. Water Sci. Technol. 2011, 63, 1037-1043. [CrossRef]

23. Sah, S.; Negussie, A. Community led total sanitation (CLTS): Addressing the challenges of scale and sustainability in rural Africa. Desalination 2009, 248, 666-672. [CrossRef]

24. Venkataramanan, V. Testing CLTS Approaches for Scalability CLTS Learning Series: Lessons from CLTS Implementation in Seven Countries; Plan International: Washington, DC, USA, 2016.

25. Crocker, J.; Abodoo, E.; Asamani, D.; Domapielle, W.; Gyapong, B.; Bartram, J. Impact Evaluation of Training Natural Leaders during a Community-Led Total Sanitation Intervention: A Cluster-Randomized Field Trial in Ghana. Environ. Sci. Technol. 2016, 50, 8867-8875. [CrossRef]

26. Kar, K.; Bongartz, P. Update on Some Recent Developments in Community-Led Total Sanitation; University of Sussex, Institute of Development Studies: Brighton, UK, 2006.

27. Vernon, N.; Bongartz, P. CHAPTER 1: Going beyond open defecation free. In Sustainable Sanitation for All; Bongartz, P., Vernon, N., Fox, J., Eds.; Practical Action Publishing: Rugby, UK, 2016.

28. Jenkins, M.W.; Scott, B. Behavioral indicators of household decision-making and demand for sanitation and potential gains from social marketing in Ghana. Soc. Sci. Med. 2007, 64, 2427-2442. [CrossRef] [PubMed]

29. Whaley, L.; Webster, J. The Effectiveness and Sustainability of Two Demand-driven Sanitation and Hygiene Approaches in Zimbabwe. J. Water Sanit. Hyg. Dev. 2011, 1, 20-36. [CrossRef]

30. Munkhondia, T.; Simangolwa, W.; Zapico, A. CLTS and sanitation marketing: Aspects to consider for a better integrated approach. In Sustainable Sanitation for All: Experences, Challenges, and Innovations; Bongartz, P., Vernon, N., Fox, J., Eds.; Practical Action Publishing: Rugby, UK, 2016.

31. Coombes, Y. CHAPTER 6: User-centred latrine guidelines-integrating CLTS with sanitation marketing: A case study from Kenya to promote informed choice. In Sustainable Sanitation for All; Bongartz, P., Vernon, N., Fox, J., Eds.; Practical Action Publishing: Rugby, UK, 2016; pp. 121-134. ISBN 9781780449272.

32. Singh, S.; Balfour, N. Sustainability of ODF Practices in Kenya; UNICEF Kenya: Nairobi, Kenya, 2015.

33. Thomas, A.; Bevan, J. Developing and Monitoring Protocol for the Elimination of Open Defecation in Sub-Saharan Africa; ODF Protocol. IRC: The Hague, The Netherlands, 2013.

34. Guiteras, R.P.; Levinsohn, J.; Mobarak, A.M. Encouraging sanitation investment in the developing world: A cluster-randomized trial. Science 2015, 348, 903-906. [CrossRef] [PubMed]

35. Nguyen, N.K.; Nguyen, H.D.; Gerwel-Jensen, L.; Nguyen, M.T.H.; Nam, D.C. Understanding Determinants of Access to Hygienic Latrines for Rural Households in Vietnam; Water Sanitation Program, World Bank: Washington, DC, USA, 2016.

36. Dumpert, J.; Ung, K. A Retrospective Review of Phase 1 of CRSHIP; WaterAid Cambodia: Phnom Penh, Cambodia, 2017.

37. Ragin, C.C. Measurement Versus Calibration: A Set-Theoretic Approach. In Oxford Handbook of Political Methodology; Oxford University Press: Oxford, UK, 2008; pp. 1-31. [CrossRef]

38. Rihoux, B.; Ragin, C.; Berg-Schlosser, D.; Meur, G.; De Rihoux, B.; Ragin, C.C. Qualitative Comparative Analysis (QCA) as an Approach. In Configurational Comparative Methods: Qualitative Comparative Analysis (QCA) and Related Techniques; SAGE Publishing: Thousand Oaks, CA, USA, 2012; pp. 1-18. [CrossRef]

39. Mukherjee, N. CHAPTER 3: Building environments to support sustainability of improved sanitation behaviours at scale: Levers of change in East Asia. In Sustainable Sanitation for All; Bongartz, P., Vernon, N., Fox, J., Eds.; Practical Action Publishing: Rugby, UK, 2016; pp. 53-82. ISBN 9781780449272.

40. UNICEF. Community-Led Total Sanitation in East Asia and Pacific: Progress, Lessons and Directions; UNICEF: Bangkok, Thailand, 2013.

41. Ministry of Rural Development National CLTS Guidelines; Government of Cambodia: Phnom Penh, Cambodia, 2014.

42. Ministry of Sanitation and Water Resources Guidelines for Targeting the Poor and Vulnerable for Basic Sanitation Services in Ghana; Government of Ghana: Accra, Ghana, 2018.

43. Kaminsky, J.; Jordan, E. Qualitative comparative analysis for WASH research and practice. J. Water Sanit. Hyg. Dev. 2017, 7, 13. [CrossRef]

44. Davis, A.; Javernick-Will, A.; Cook, S.M. The use of qualitative comparative analysis to identify pathways to successful and failed sanitation systems. Sci. Total Environ. 2019, 663, 507-517. [CrossRef] [PubMed]

45. CRSHIP. Fostering Collective Action To Improve Sanitation in Rural; Plan International Cambodia: Phnom Penh, Cambodia, 2018

46. World Bank GDP per Capita Growth (Annual \%)—Cambodia. Available online: https://data.worldbank.org/indicator/NY.GDP. PCAP.KD.ZG?locations=KH. (accessed on 17 April 2020).

47. Mukherjee, N. Factors Associated with Achieving and Sustaining Open Defecation Free Communities: Learning from East Java; Water Sanitation Program, World Bank: Washington, DC, USA, 2011.

48. Huda, E. Natural Leaders Emerged through Community Led Total Sanitation (CLTS) Approach in Bangladesh (Profile and Market Promotion); CLTS Knowledge Hub, Institute for Development Studies (IDS): Brighton, UK, 2009. 
49. Otieno, P. Engaging Natural Leaders in Community-Led Total Sanitation in Nigeria; WaterAid Nigeria: Lagos, Nigeria, 2011.

50. Haq, A.; Bod, B. Hunger, Subsidies and Process Facilitation: Challenges for Community Led Total Sanitation in Bangladesh; CLTS Knowledge Hub, Institute for Development Studies (IDS): Brighton, UK, 2009.

51. Dyalchand, A.; Kale, M.; Vasudevan, S. What Communication and Institutional Arrangements Influence Sanitation Related Social Norms in Rural India? CLTS Knowledge Hub, Institute for Development Studies (IDS): Brighton, UK, 2009.

52. Jha, H.B. An Assessment of CLTS Projects and Formulation of the Strategy on Sanitation Promotion; Centre for Economic and Technical Studies Pvt. Ltd.: Lalitpur, Nepal, 2007.

53. Pardeshi, G.; Shirke, A.; Jagtap, M. SWOT analysis of total sanitation campaign in Yavatmal district of Maharashtra. Indian J. Community Med. 2008, 33, 255-259. [CrossRef]

54. USAID. Ghana WASH Project-Lessons Learned: Hybrid CLTS Approach to Improving Sanitation; USAID: Washington, DC, USA, 2014.

55. O'Reilly, K.; Louis, E. The toilet tripod: Understanding successful sanitation in rural India. Health Place 2014, 29, 43-51. [CrossRef]

56. UNICEF. WCARO Roll-Out Evaluation of "Community Led Total Sanitation" in West and Centra Africa; UNICEF: Dakar, Senegal, 2011.

57. Venkataramanan, V.; Shannon, A. CLTS Learning Series: Lessons from CLTS Implementation in Seven Countries; The Water Institute at UNC: Chapel Hill, NC, USA, 2016.

58. Harter, M.; Inauen, J. The role of social identification for achieving an open-defecation free environment: A cluster-randomized, controlled trial of Community-Led Total Sanitation in Ghana. J. Environ. Psychol. 2019, 101360. [CrossRef]

59. Hirai, M.; Graham, J.P.; Sandberg, J. Understanding women's decision making power and its link to improved household sanitation: The case of Kenya. J. Water Sanit. Hyg. Dev. 2016, 6, 151-160. [CrossRef]

60. USAID Water CKM Project. Evaluation Report: Madagascar Rural Access to New Opportunities for Health and Prosperity (RANO-HP) Sustainability Evaluation; USAID: Washington, DC, USA, 2017.

61. Adeyeye, A. Gender and Community-Led Total Sanitation: A Case Study of Ekiti State, Nigeria. Trop. Resour. 2011, $30,1-27$.

62. Arandan, S.N. Role of Gender on Community Led Total Sanitation Processes in Kanyingombe Community Health Unit, Rongo Sub County, Kenya. Eur. Int. J. Sci. Technol. 2016, 5, 89-98.

63. Cavill, S.; Roose, S.; Stephen, C.; Wilbur, J. CHAPTER 15: Putting the hardest to reach at the heart of the Sustainable Development Goals. In Sustainable Sanitation for All; Bongartz, P., Vernon, N., Fox, J., Eds.; Practical Action Publishing: Rugby, UK, 2016; pp. 245-266. ISBN 9781780449272.

64. O'Reilly, K. Combining sanitation and women's participation in water supply: An example from Rajasthan. Dev. Pract. 2010, 20, 45-46. [CrossRef]

65. Burt, Z.; Nelson, K.L.; Ray, I. Towards Gender Equality Through Sanitation Access; UN Women Discussion Papers; UN Women: Berkeley, CA, USA, 2016.

66. Plan Uganda. Research on the Impact of Gender on Community-Led Total Sanitation Processes; Plan Uganda: Kampala, Uganda, 2012.

67. Cameron, L.A.; Olivia, S.; Shah, M. Initial Conditions Matter: Social Capital and Participatory Development. SSRN Electron. J. 2015, 35. [CrossRef] 